\title{
Pluripotency of mesenchymal stem cells derived from adult marrow
}

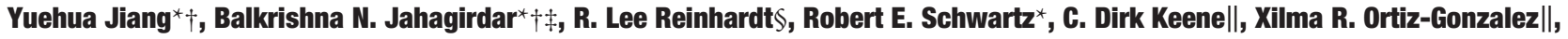 \\ Morayma Reyes*, Todd Lenvik*, Troy Lund, Mark Blackstad ${ }^{*}$, Jingbo Du*, Sara Aldrich, Aaron Lisberg*, Walter C. Low\|, \\ David A. Largaespada $\uparrow$ \& Catherine M. Verfaillie ${ }^{\star} \ddagger$ \\ * Stem Cell Institute, $\$$ Division of Hematology, Oncology and Transplantation, Department of Medicine, $\$$ Department of Microbiology, Center for \\ Immunology, || Department of Neurosurgery, and $\mid$ Department of Genetics, Cell Biology and Development, University of Minnesota Medical School, Minneapolis, \\ Minnesota 55455, USA \\ $\uparrow$ These authors contributed equally to this work
}

We report here that cells co-purifying with mesenchymal stem cells-termed here multipotent adult progenitor cells or MAPCsdifferentiate, at the single cell level, not only into mesenchymal cells, but also cells with visceral mesoderm, neuroectoderm and endoderm characteristics in vitro. When injected into an early blastocyst, single MAPCs contribute to most, if not all, somatic cell types. On transplantation into a non-irradiated host, MAPCs engraft and differentiate to the haematopoietic lineage, in addition to the epithelium of liver, lung and gut. Engraftment in the haematopoietic system as well as the gastrointestinal tract is increased when MAPCs are transplanted in a minimally irradiated host. As MAPCs proliferate extensively without obvious senescence or loss of differentiation potential, they may be an ideal cell source for therapy of inherited or degenerative diseases.

Embryonic stem (ES) cells are pluripotent cells derived from the inner cell mass of the blastocyst that can be propagated indefinitely in an undifferentiated state. ES cells differentiate to all cell lineages in vivo and differentiate into many cell types in vitro. Although ES cells have been isolated from humans ${ }^{1}$, their use in research as well as therapeutics is encumbered by ethical considerations ${ }^{2}$. Stem cells also exist for most tissues, including haematopoietic ${ }^{3}$, neural ${ }^{4}$, gastrointestinal $^{5}$, epidermal ${ }^{6}$, hepatic ${ }^{7}$ and mesenchymal stem cells ${ }^{8}$. Compared with ES cells, tissue-specific stem cells have less self-renewal ability and, although they differentiate into multiple lineages, they are not pluripotent.

Until recently, it was thought that tissue-specific stem cells could only differentiate into cells of the tissue of origin; however, recent studies suggested that tissue-specific stem cells can differentiate into lineages other than the tissue of origin. After transplantation of bone marrow or enriched haematopoietic stem cells (HSC), skeletal myoblasts ${ }^{9,10}$, cardiac myoblasts ${ }^{11,12}$, endothelium ${ }^{11-14}$, hepatic and biliary duct epithelium ${ }^{15-17}$, lung, gut and skin epithelia ${ }^{18}$, and neuroectodermal cells of donor origin have been detected ${ }^{19-22}$. Some but not other studies demonstrated that neural stem cells $^{23,24}$ as well as muscle cells ${ }^{25,26}$ may differentiate into haematopoietic cells. When injected into a blastocyst, neural stem cells contribute to a number of tissues of the chimaeric mouse embryo ${ }^{27}$; however, most studies did not conclusively demonstrate that a single tissue-specific stem cell differentiates into functional cells of multiple tissues.

We identified a rare cell within human bone marrow mesenchymal stem cell cultures that can be expanded for more than 80 population doublings. This cell differentiates not only into mesenchymal lineage cells but also endothelium ${ }^{28,29}$ and endoderm $^{30}$. We show that cells capable of differentiating in vitro to cells of the three germ layers can be selected from rodent bone marrow. These cells contribute to most somatic tissues when injected into an early blastocyst and engraft in vivo, where they differentiate into tissue-specific cell types in response to cues provided by different organs.

\section{Culture of undifferentiated mouse and rat MAPCs}

To isolate MAPCs from murine bone marrow, we used methods identical to those used for human (h)MAPCs ${ }^{28}$, except that murine
(m)MAPCs, but not hMAPCs, required leukaemia inhibitory factor (LIF) for expansion. (A detailed description of the culture method can be found in Supplementary Information Table 1.) We have been able to culture several mMAPC populations for more than 120 population doublings (Fig. 1a). The phenotype of mMAPCs in fresh bone marrow is unknown. The phenotype of cultured mMAPCs is CD34, CD44, CD45, c-Kit, and major histocompatibility complex (MHC) class I and II negative; mMAPCs express low levels of Flk-1, Sca-1 and Thy-1, and higher levels of CD13 and stage-specific antigen I (SSEA-I $)^{1}$ (Fig. 1b). The morphology and phenotype were similar after 30 to more than 120 population doublings (Supplementary Information Fig. 1). The mMAPC phenotype is similar to that of hMAPC ${ }^{28}$ but different from that of murine haemopoietic stem cells with 'transdifferentiation' potential ${ }^{11,17,18,25}$. mMAPCs were $8-10 \mu \mathrm{m}$ in diameter with a large nucleus and scant cytoplasm (Supplementary Information Fig. 1a). Average telomere length (ATL) of mMAPCs cultured for 40 population doublings was 27 kilobases $(\mathrm{kb})$; when re-tested after 102 population doublings, ATL remained unchanged (Fig. 1c).

Similar results were obtained when we isolated and cultured MAPCs from bone marrow of Sprague-Dawley rats $(n=3)$. We have expanded rat (r)MAPCs for more than 100 population doublings (Supplementary Information Fig. 2a). Successful culture of rMAPCs required addition of LIF to epidermal growth factor (EGF) and platelet-derived growth factor (PDGF)-BB. rMAPCs were MHC class I and class II negative, CD44 negative (data not shown), expressed high levels of telomerase, and the telomeres have not shortened in culture for 100 population doublings (Supplementary Information Fig. 2b).

The finding that rodent but not hMAPCs require addition of LIF to the culture medium is similar to results for ES cells: human ES cells seem to be LIF-independent ${ }^{31}$ whereas murine ES cells require LIF for ex vivo maintenance ${ }^{32}$. Quantitative reverse transcription polymerase chain reaction (Q-RT-PCR) showed that two transcription factors important in maintaining undifferentiated ES cells, Oct-4 (ref. 33) and Rex-1 (ref. 34), were expressed in mMAPCs: Rex-1 at levels similar to mouse ES cells and Oct-4 at levels 1,000-fold lower than ES cells (Fig. 1d). 


\section{In vitro differentiation of single mMAPCs and rMAPCs}

Approximately $1 \%$ of wells seeded with ten $\mathrm{CD} 45^{-}$TER $119^{-}$bone marrow monocular cells (BMMNCs) yielded continuous growing cultures, suggesting that 1 out of 1,000 CD45 ${ }^{-}$TER119- BMMNCs is capable of initiating MAPC cultures, and that progeny generated from ten cells is probably derived from one cell. To definitively prove that a single cell gives rise to continuous growing cultures and differentiated progeny, we used retroviral marking (Fig. 2; see also Supplementary Information Table 2). After sub-cloning at ten cells per well, three murine and two rat enhanced green fluorescent protein-expressing $\left(\mathrm{eGFP}^{+}\right)$cell populations were selected and culture-expanded for more than 100 population doublings. One hundred per cent of cells continued to express GFP after expansion. Southern blot analyses showed that a single retroviral insert was detected in one mMAPC and one rMAPC population derived from ten initial cells (Fig. 2). The same single retroviral insert was also seen in seven subclones of the rMAPC population, demonstrating that progeny of only a single eGFP-transduced mMAPC or rMAPC gave rise to the continuous growing population $s^{35,36}$. We sequenced the genomic flanking region $3^{\prime}$ from the retrovirus using splinkerette PCR, which detects a single retroviral insert in as few as $5 \times 10^{3}$ cell $^{37}$. A single retroviral insertion site was detected in the mMAPC and rMAPC population (Supplementary Information Table 2). Presence of the flanking region was confirmed by PCR using primers designed in the murine stem cell virus (MSCV) long terminal repeat (LTR) and in the mouse or rat genomic flanking sequence $3^{\prime}$ of the insertion site.

We next tested the in vitro differentiation ability of mMAPCs and

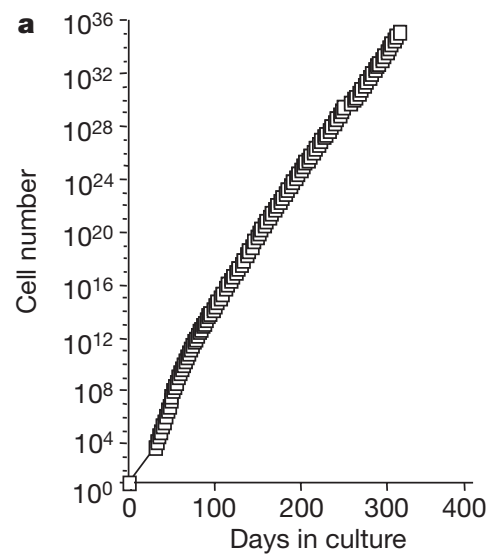

c

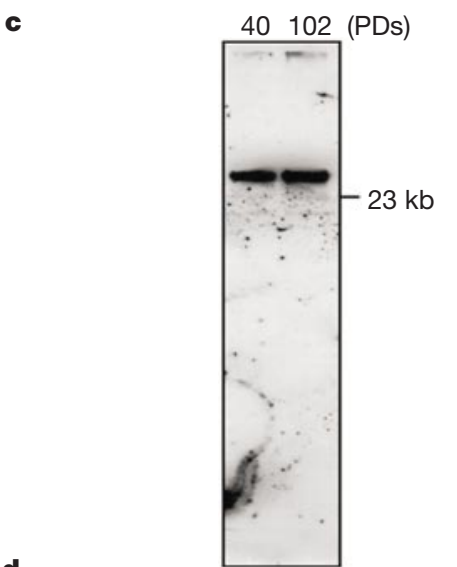

d

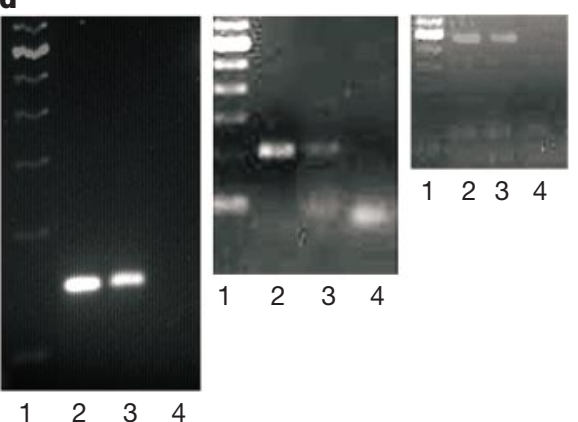

b
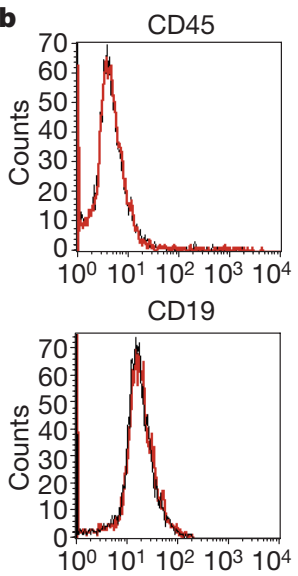
C-Kit
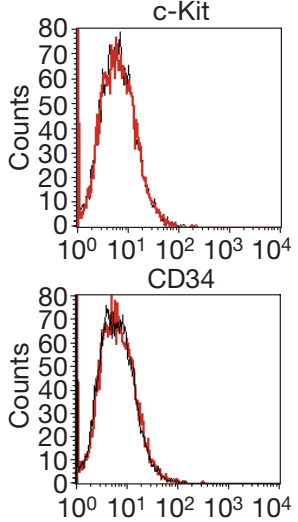

$\mathrm{MHC}$ II

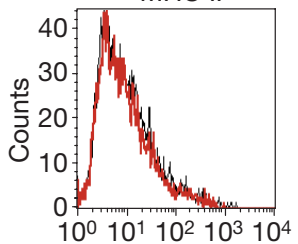

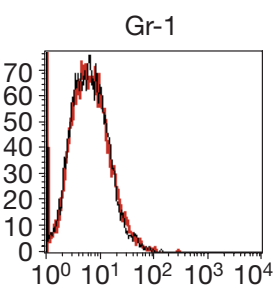

CD3
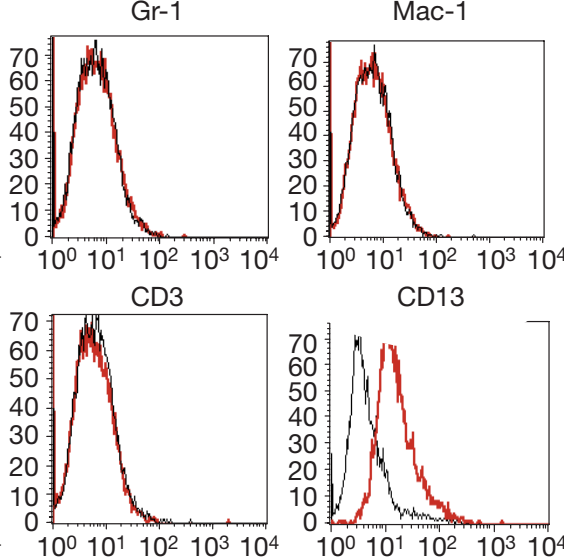

CD13
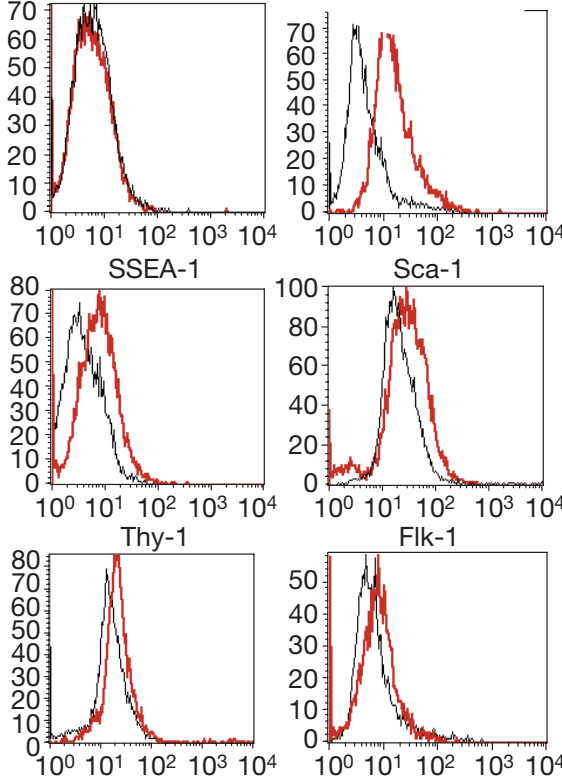

$\mathrm{MHC}$ I
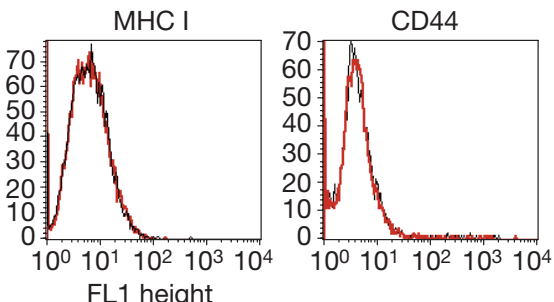

Figure 1 Characteristics of mMAPCs. Mouse BMMNCs were plated with EGF, PDFG-BB, and LIF on FN-coated plates. After 3-4 weeks, bead-selected CD45 ${ }^{-} /$TER $119^{-}$cells were plated at ten cells per well in $\mathrm{FN}$-coated 96 -well plates in the same medium, and expanded at $0.5-1.5 \times 10^{3} \mathrm{~cm}^{-2}$. a, Cells were enumerated at each passage under a haemocytometer. b, mMAPCs cultured for 120 population doublings were labelled with FITC-coupled antibodies against CD45, Gr-1, Mac-1, CD19, CD3, CD13, c-Kit, SSEA-1, Sca-1, CD34, Thy-1, Flk-1, MHC class II $\left(I-A^{k}\right), M H C$ class I $\left(H-2 K^{k}\right), C D 44$ or immunoglobulin isotype control antibodies. Cells were analysed using a FACS-Calibur. Black line, control immunoglobulin; red line, specific antibody. c, Telomere length of mMAPCs cultured for 40 population doublings (PDs) (lane 1) and 102 population doublings (lane 2) ${ }^{28}$. d, Quantitative RT-PCR for Rex- 1 (left), Oct-4 (middle) and $\beta$-actin (right). Lane 1, ladder; lane 2, ES cells; lane 3, MAPCs; lane 4, no-template control (see Methods and Supplementary Information Table 1). 
rMAPCs by adding cytokines chosen on the basis of what has been described for differentiation of hMAPC or ES cells to mesoderm, neuroectoderm and endoderm. Differentiation required that MAPCs be replated at $1-2 \times 10^{4}$ cells $\mathrm{cm}^{-2}$ in medium without serum, EGF, PDGF-BB and LIF, but with lineage-specific cytokines. Studies were done using two independently derived ROSA26, two C57BL/6 and one rat MAPC population expanded for 40-120 population doublings, as well as with eGFP-transduced clonal mMAPCs (repeated after 50, 80 and 120 population doublings) and clonal rMAPCs (repeated after 50 and 80 population doublings). Differentiation was similar when MAPCs cultured for 40 to more than 100 population doublings were used. No differences were seen between transduced and untransduced cells. Most data shown are therefore from the clonal $\mathrm{eGFP}^{+}$mMAPCs (Fig. 3) and clonal $\mathrm{eGFP}^{+}$rMAPCs (Supplementary Information Fig. 3).

As an example of mesoderm, we induced differentiation to endothelium. Undifferentiated mMAPCs or rMAPCs were negative for CD31, CD62E or von Willebrand factor (vWF) (data not shown), but expressed low levels of Flk-1 (Fig. 1b). When mMAPCs (Fig. 3) or rMAPCs (Supplementary Information Fig. 3) were cultured on fibronectin (FN) with $10 \mathrm{ng} \mathrm{ml}^{-1}$ vascular endothelial growth factor (VEGF)-B for 14 days, more than $90 \%$ of MAPCs acquired an endothelial phenotype and expressed CD31, Flk-1 and vWF. All cells staining positive for vWF also expressed eGFP, whereas a small population of $\mathrm{eGFP}^{+}$'fibroblast-like' cells not staining positive for vWF remained in the culture (Fig. $3 \mathrm{a}-\mathrm{h}$ ).

Neuroprogenitors can be expanded with PDGF-BB and induced to differentiate by removal of PDGF and addition of basic fibroblast growth factor (bFGF) ${ }^{38}$. Therefore, we cultured mMAPCs (Fig. 3) and rMAPCs (Supplementary Information Fig. 3) in FN-coated
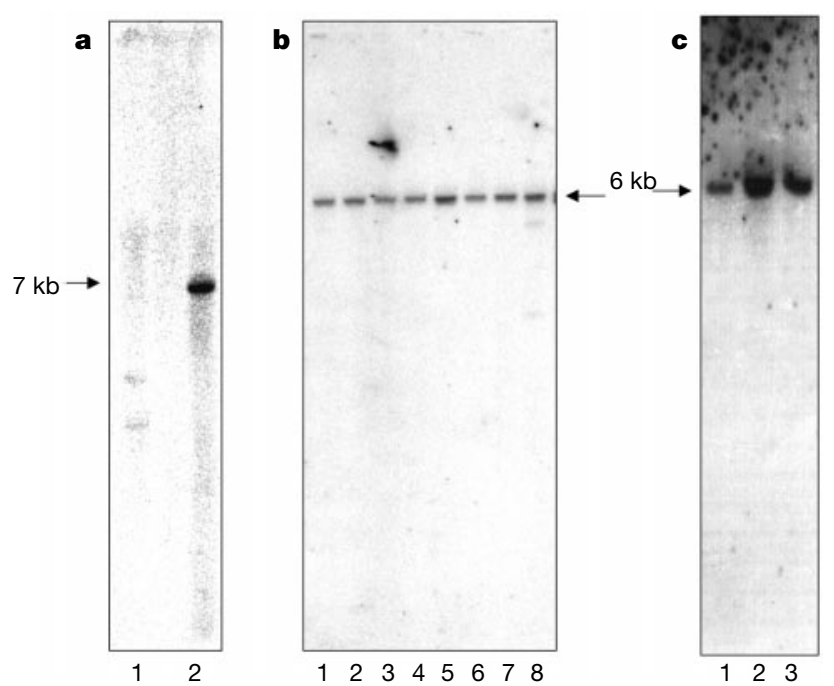

Figure 2 Single cell origin of mMAPC and rMAPC cultures initiated from ten cells per well, and their differentiated progeny (see also Supplementary Information Table 2). Mouse or rat BMMNCs, transduced with an MSCV-eGFP retrovirus ${ }^{49}$, were depleted of CD45 TER $119^{+}$cells, and eGFP ${ }^{+}$cells were replated at ten cells per well and expanded for more than 100 population doublings. DNA from MAPCs or their differentiated progeny (Fig. 3 and Supplementary Information Fig.3) was digested overnight with EcoRI or BamHI (cut only once in the MSCV-eGFP provirus), fragments were separated by electrophoresis, and probed with a ${ }^{32} \mathrm{P}$-labelled eGFP cDNA probe. a, DNA extracted from pooled mMAPCs differentiated after 80 population doublings into endothelial, neuroectodermal and hepatic cells (see Fig. 3). A single retroviral insert at $7 \mathrm{~kb}$ was seen. b. Undifferentiated rMAPCs (lane 1) and seven subpopulations of rMAPCs after 75 population doublings, subcultured at 100 cells and expanded for 20 population doublings (lanes 2-8). A single retroviral insert at $6 \mathrm{~kb}$ was seen. c, rMAPCs expanded for 85 population doublings differentiated to the endothelial (lane 1), neuroectodermal (lane 2) and hepatic (lane 3) cells. A single retroviral insert at $6 \mathrm{~kb}$ was seen. wells without PDGF-BB and EGF, but with $100 \mathrm{ng} \mathrm{ml}^{-1} \mathrm{bFGF}^{38}$. After 14 days, $15 \pm 4 \%$ of MAPCs acquired morphologic and phenotypic characteristics of astrocytes (glial acidic fibrillary protein $(\mathrm{GFAP})^{+}$), $12 \pm 3 \%$ of oligodendrocytes (galactocerebroside $(\mathrm{GalC})^{+}$) and $68 \pm 9 \%$ of neurons (neurofilament-200 (NF$200)^{+}$). NF-200, GFAP or GalC were never found in the same cell. More than $90 \%$ of $\mathrm{eGFP}^{+}$cells were labelled with neuroectodermal markers. Quantitative RT-PCR of mMAPCs treated with bFGF confirmed expression of neuroectodermal genes (Supplementary Information Table 3). After culture with bFGF, levels of Otx2 messenger RNA increased more than 50 -fold by day 2 and became maximal by day 5 . On day 4, Otx1 mRNA was upregulated 3-5-fold, and on day 5 levels of Pax2, Pax 5 and nestin mRNA increased 400800 -fold over undifferentiated mMAPCs ${ }^{39}$. When mMAPCs were cultured sequentially with $100 \mathrm{ng} \mathrm{ml}^{-1} \mathrm{bFGF}, 10 \mathrm{ng} \mathrm{ml}^{-1}$ FGF- 8 and finally $10 \mathrm{ng} \mathrm{ml}^{-1}$ brain-derived neurotrophic factor (BDNF), a more mature phenotype was seen (Fig. 3i-q). Thirty percent of cells expressed markers of dopamine-containing neurons (dopadecarboxylase (DDC) and tyrosine hydroxylase (TH) positive), $20 \%$ of serotonin-containing (serotonin positive) neurons and $50 \%$ of $\gamma$-aminobutyric acid (GABA)-containing (GABA positive) neurons. Neuron-like cells became polarized, as Tau and MAP2 were expressed in axonal and somatodendritic compartments, respectively (Fig. $3 \mathrm{~m})$.

We next tested whether mMAPCs (Fig. 3) or rMAPCs (Supplementary Information Fig. 3) differentiate to endodermal cells. As described more extensively elsewhere ${ }^{30}$, when replated on matrigel with $10 \mathrm{ng} \mathrm{ml}^{-1} \mathrm{FGF}-4$ and $20 \mathrm{ng} \mathrm{ml}^{-1}$ hepatocyte growth factor (HGF), approximately $60 \%$ of mMAPCs (Fig. 3a-h) or rMAPCs acquired epithelioid morphology and $10 \%$ of cells became binucleated. Sixty per cent of cells stained positive for albumin, cytokeratin (CK)18, and HNF-1. Figure 3a-h shows that all cells staining positive for CK18 were also $\mathrm{eGFP}^{+}$. We recently showed that these epithelioid cells have functional characteristics of hepatocytes, including urea and albumin production, phenobarbitalinducible p450, gluconeogenesis and low-density lipoprotein uptake ${ }^{30}$.

Southern blot analyses and flanking region PCR demonstrated that differentiated $\mathrm{eGFP}^{+}$mMAPCs and rMAPCs contained the identical single retroviral insert found in undifferentiated MAPCs (Fig. 2 and Supplementary Information Table 2). As 100\% of differentiated cells were $\mathrm{eGFP}^{+}$(Fig. 3a-h) and only a single retroviral insertion site was present, these studies show that a single MAPC differentiates into cells with morphologic, phenotypic and functional characteristics of cells representing the three germ layers.

\section{Single MAPCs contribute to most somatic tissues}

To further determine the extent of differentiation of MAPCs, we assessed their ability to contribute to various tissues by introducing MAPCs into an early blastocyst. One or 10-12 ROSA26 MAPCs obtained after 55-65 population doublings were microinjected into 3.5-day-old blastocysts of C57BL/6 mice. Blastocysts were transferred to foster mothers, and mice were allowed to develop and be born (Table 1). The number of litters born and animals per litter were in line with the birth rate seen in other studies during this period. Animals born from microinjected blastocysts were of similar size as normal animals and did not display overt abnormalities.

Chimaerism was assessed by comparing levels of $\mathrm{Neo} / \beta-\mathrm{Gal}^{40}$ in tail clippings of 4-week-old animals with that of tissue of ROSA26 mice using Q-PCR. Chimaerism could be detected in $80 \%$ of mice derived from blastocysts in which 10-12 mMAPCs were injected and in 33\% of mice derived from blastocysts microinjected with 1 mMAPC (Table 1). In both sets of animals, chimaerism ranged between $0.1 \%$ and $45 \%$. Absence of chimaerism in some of the microinjected blastocysts may indicate that mMAPCs are not completely homogeneous. Alternatively, technical problems with injection of a single cell may be responsible for the failure of $66 \%$ of 
single mMAPCs to contribute to development of the mouse.

Animals were killed at 6-20 weeks. Some mice were frozen in liquid nitrogen, thin whole-mouse sections cut as described ${ }^{41}$, and stained with 5-bromo-4-chloro-3-indolyl- $\beta$-D-galactoside (X-gal). Shown in Fig. $4 \mathrm{i}$ is a representative animal, non-chimaeric as determined by tail clip analysis, derived from a blastocyst in which a single MAPC was injected. No X-gal staining was seen. In contrast, the animal in Fig. 4 j, which was $45 \%$ chimaeric by tail clip analysis, had the contribution of a single ROSA26-derived MAPC to many somatic tissues.

We also collected multiple organs separately and determined the presence of mMAPC-derived cells by X-gal staining (Fig. $4 \mathrm{a}-\mathrm{h}$; see also Supplementary Information Fig. 4) and staining with an anti$\beta$-gal fluorescein isothiocyanate (FITC) antibody (Fig. 5). Chimaeric animals that had $\mathrm{Neo} / \beta-\mathrm{Gal}^{+}$cells, as determined by PCR in the tail clip analysis, had a contribution of the ROSA26-derived MAPC to many tissues, including brain, retina (not shown), lung, myocardium, skeletal muscle, liver, intestine, kidney, spleen, bone marrow, blood (not shown), and skin (as shown by X-gal staining, Fig. $4 \mathrm{a}-\mathrm{h}$; see also Supplementary Information Fig. 4). $\beta$-gal ${ }^{+}$cells expressed markers typical for the tissue in which they had incorporated. $\beta$-gal ${ }^{+}$cells in bone marrow, spleen and blood co-stained for CD45, Gr-1, Mac-1, CD19 and CD3 antigens (Fig. 5). Because of the haematopoietic chimaerism, we used triple-colour immunofluorescence to assure that $\beta$-gal ${ }^{+}$cells in solid organs were not mere haematopoietic cells. $\beta$-gal ${ }^{+}$cells co-stained for pan-CK in the lung and intestine, and for CK18 in the liver (Fig. 5). We also detected $\mathrm{CD}_{4}{ }^{+} \mathrm{CK}^{-} \beta-\mathrm{Gal}^{+}$cells in these organs. However, no cell costained for all three antigens (that is, $\beta$-gal, CD45 and CK). $\beta$-gal ${ }^{+}$ cells co-stained for dystrophin in skeletal muscle and cardiac troponin-I in the myocardium (Fig. 5). $\beta$-gal ${ }^{+}$cells gave rise to neurons $\left(\mathrm{Neu}-\mathrm{N}^{+}\right)$and astrocytes $\left(\mathrm{GFAP}^{+}\right)$throughout the entire brain, including the cortex, striatum, hippocampus, thalamus and cerebellum (Fig. 5). In the cingulate cortex, $\beta$-gal ${ }^{+}$neurons and astrocytes were present, whereas in the underlying corpus callosum, $\beta$-gal ${ }^{+}$astrocytes and presumed oligodendroglia were found. In the hippocampus, most of the granule cells of the dentate gyrus and pyramidal cells of the hilus were $\beta$-gal ${ }^{+}$, and were interspersed with $\beta$-gal ${ }^{+}$, MAPC-derived astrocytes.

It has been reported that after injection of ROSA26-derived neural stem cells into murine blastocysts, LacZ-expressing cells are found with varying degrees not only in the brain, but also in some mesodermal and endodermal tissues of the chimaeric mouse embryo $^{27}$. Our results confirm and extend these studies, as we show that single MAPCs generate balanced chimaeras, that is, contribute to most somatic cell types, and that chimaerism can be detected not only in mouse embryos, but also in mice that were 6-20 weeks old. Although some LacZ ${ }^{+}$cells were seen in gonads, we have not yet performed breeding experiments to test whether MAPCs contribute to the germ line.
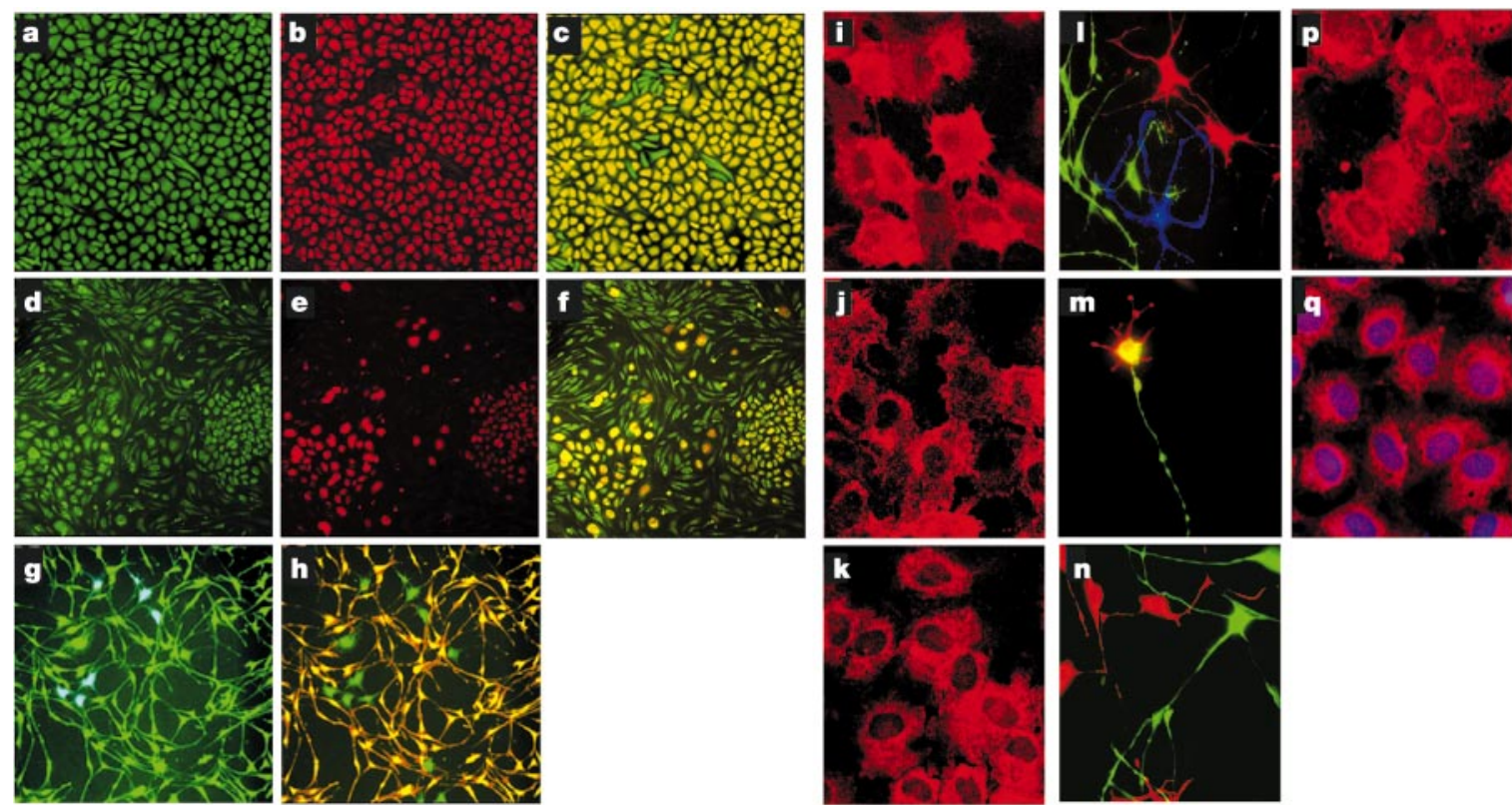

Figure $\mathbf{3}$ In vitro differentiation of mMAPCs to endothelium, neuroectoderm and endoderm. a-h, Clonal eGFP ${ }^{+}$mMAPCs treated with VEGF (a-c), FGF-4 + HGF (d-f) or bFGF (g, h) for 14 days. Cultures were stained with anti-vWF labelled with Cy3 (b), antialbumin-Cy3 (e), anti-GFAP-Cy5 (g) or anti-NF200-Cy3 (h). c, f, $\mathbf{g}$ and $\mathbf{h}$ show an overlay of Cy3 or Cy5 staining with eGFP. a, c, d, f, $\mathbf{g}$ and $\mathbf{h}$ show that $100 \%$ of cells were eGFP positive ( $\times 10$ magnification). i-k, eGFP ${ }^{+}$mMAPCs treated with VEGF for 14 days were stained with antibodies against CD31-Cy3 (i), Flk-1-Cy3 (j) or vWF-Cy3 (k) ( $\times 60$ magnification). I-0, ROSA26 mMAPCs treated with bFGF for 14 days were stained with antibodies against GFAP-Cy3, FITC-labelled NF200 and anti-GalC-Cy5 (I) $(\times 20$
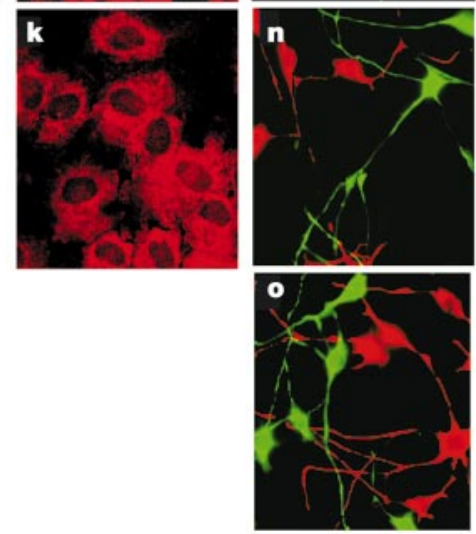

magnification). Alternatively, ROSA26 mMAPCs treated sequentially with bFGF, FGF-8 and BDNF were stained with antibodies against MAP2-Cy3 and FITC-labelled anti-Tau (m), GABA-Cy3 and FITC-labelled DDC (n), or TH-Cy3 and FITC-labelled serotonin (o) ( $\times 40$ magnification). p, q, eGFP ${ }^{+}$mMAPCs treated with FGF-4 and HGF for 14 days stained with antibodies against CK18-Cy3 (p), or albumin-Cy3 and HNF1-Cy5 (q) ( $\times 60$ magnification). Colour staining: Cy3, red; FITC, green; Cy5, blue. Double positive for FITC and Cy3, yellow. In $\mathbf{q}$, the nucleus area is positive for HNP1-Cy5 and weakly positive for Cy3, giving purple. Magnification: $\mathbf{a}-\mathbf{h}, \times 10 ; \mathbf{i}-\mathbf{k}, \times 60 ; \mathbf{I}, \times 20 ; \mathbf{m}-\mathbf{0}, \times 40$; p, q, $\times 60$. 


\begin{tabular}{|c|c|c|c|c|c|c|c|}
\hline \multirow[t]{2}{*}{ MAPCs per blastocyst } & \multirow[t]{2}{*}{ Litters born } & \multirow[t]{2}{*}{ No. of pups born } & \multicolumn{5}{|c|}{ Neo-positive by Q-PCR (\%) } \\
\hline & & & 0 & $1-10$ & 10-20 & $20-40$ & $>40$ \\
\hline $10-12$ & 4 of 11 & 22 & 5 of $22(23 \%)$ & 13 of $22(59 \%)$ & 2 of $22(9 \%)$ & 1 of $22(4.5 \%)$ & 1 of $22(4.5 \%)$ \\
\hline 1 & 3 of 5 & 15 & 8 of $15(53 \%)$ & 5 of $15(33 \%)$ & 0 of $15(0 \%)$ & 0 of $15(0 \%)$ & 2 of $15(13 \%)$ \\
\hline
\end{tabular}
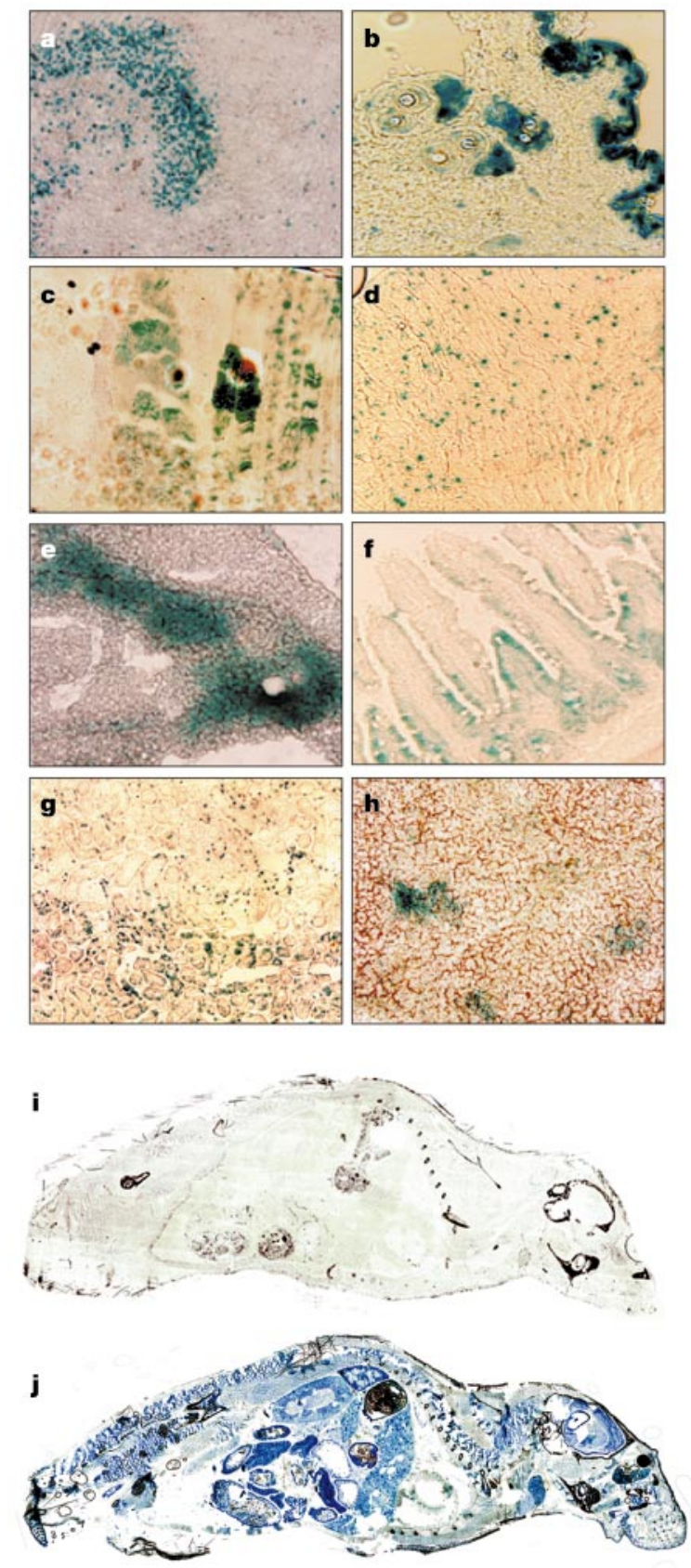

Figure 4 Chimaerism detection by X-gal staining and anti- $\beta$-gal staining in animals generated from blastocysts microinjected with a single ROSA26 MAPC (see also Table 1 and Supplementary Information Fig. 4). a-h, Images from X-gal-stained individual organs from a $45 \%$ chimaeric mouse, determined by Q-PCR for Neo on tail clip. Tissue sections were from: brain (a), skin (b), skeletal muscle (c), myocardium (d), liver (e), small intestine (f), kidney (g) and spleen (h). i, j, Images from an X-gal-stained section through a mouse that was not chimaeric (i) or was $45 \%$ chimaeric (j). Magnification, $\times 20$.

\section{mMAPCs engraft and differentiate in tissue-specific cells}

We next tested whether mMAPCs infused intravenously in postnatal animals engraft and differentiate in tissue-specific cells. To avoid rejection by recipient animals, undifferentiated ROSA26 MAPCs were injected by means of the tail vein into non-irradiated or irradiated (250 cGy) 6-8-week-old non-obese diabetic/severe combined immunodeficient (NOD/SCID) recipients. Engraftment of $\beta$-gal/Neo-containing cells was tested by immunohistochemistry (for $\beta$-gal) and Q-PCR (for Neo), 4-24 weeks after transplantation (Table 2 and Fig. 6). Engraftment, defined as more than $1 \% \beta-$ gal $^{+}$ cells by immunofluorescence and/or Q-PCR, was seen in haematopoietic tissues (blood, bone marrow and spleen) and epithelium of lung, liver and intestine of all recipient animals, and was similar in animals analysed 4-24 weeks after transplantation.

$\beta$-gal ${ }^{+}$cells in bone marrow and spleen co-stained for CD45 (Fig. 6). Thirty-eight to $62 \%$ of bone marrow $\beta$-gal ${ }^{+}$cells co-stained for Gr-1, 9-27\% for Mac-1, 18-31\% for CD19, and $4-11 \%$ for TER119 (Supplementary Information Table 4). Similar results were seen for blood (not shown). No $\beta$-gal ${ }^{+} \mathrm{CD}^{+} \mathrm{T}$ cells were seen in blood, bone marrow or spleen even though $\beta$-gal ${ }^{+} \mathrm{CD}^{+} \mathrm{T}$ cells were present in chimaeric mice. The reason for this is unknown. Engraftment in the spleen occurred mostly as clusters of donor cells, consistent with the hypothesis that when MAPCs home to the spleen, they proliferate locally and differentiate to form a colony of donor cells, similar to colony-forming unit-spleen (CFU-S). Differentiation of mMAPCs into haematopoietic cells cannot be attributed to contamination of the mMAPCs with HSC. BMMNCs are depleted of $\mathrm{CD} 45^{+}$cells by column selection before MAPC cultures are initiated. MAPCs are CD3, Gr-1, Mac-1, CD19, CD34 and CD45 negative (Fig. 1), and early mesodermal or haematopoietic transcription factors, including brachyury, GATA-2 and GATA-1 (ref. 42), are not expressed in mMAPCs (complementary DNA array data; not shown). Furthermore, culture conditions for mMAPCs are not supportive for HSC and all attempts at inducing haematopoie-

\begin{tabular}{|c|c|c|c|c|c|c|c|c|}
\hline \multirow[t]{2}{*}{ Animal } & \multirow{2}{*}{$\begin{array}{c}\text { Time } \\
\text { (weeks) }\end{array}$} & \multirow[t]{2}{*}{ Radiation } & \multicolumn{6}{|c|}{ Engraftment levels (\%) } \\
\hline & & & Marrow & Blood & Spleen & Liver & Lung & Intestine \\
\hline 1 & 4 & No & $2(1)$ & 2 & 5 & 7 & 4 & 2 \\
\hline 2 & 5 & No & $3(4)$ & 4 & 5 & 9 & 5 & 3 \\
\hline 3 & 10 & No & 1 & 3 & 3 & 6 & 3 & 2 \\
\hline 4 & 16 & No & 4 & 2 & 3 & 4 & 3 & $4(4.9)$ \\
\hline 5 & 24 & No & 3 & 2 & 3 & 6 & 4 & 1 \\
\hline 6 & 8 & Yes & $8(8)$ & 6 & 4 & 5 & $2(1.1)$ & 7 \\
\hline 7 & 8 & Yes & 10 & 8 & 7 (7.3) & 4 & 6 & 8 \\
\hline 8 & 8 & Yes & 5 & 8 & 3 & 5 & 5 & 6 \\
\hline 9 & 8 & Yes & 7 & 5 & 5 & 6 & 4 & 6 \\
\hline 10 & 10 & Yes & $5(6)$ & 7 & 9 (12.5) & 5 & 2 & 8 \\
\hline 11 & 11 & Yes & 8 & 8 & 6 & 5 & 3 & $10(11.9)$ \\
\hline 12 & 11 & Yes & 6 & 5 & 4 & $8(6.2)$ & $10(12.3)$ & 8 \\
\hline SR-1 & 7 & Yes & 6 & 7 & 5 & $1(1.7)$ & 5 & 8 \\
\hline SR-2 & 10 & Yes & 5 & 4 & 8 & 3 & 4 & 6 \\
\hline
\end{tabular}

Engraftment levels were determined by immunofluorescence or Q-PCR. $10^{6}$ ROSA26 MAPCs were injected intravenously in 6-8-week-old NOD/SCID mice, maintained according to IACUC guidelines. Recipient mice were either non-irradiated or irradiated with 250 cGy ( $57 \mathrm{cGy} \mathrm{min}^{-1}$ by a mark 1 caesium irradiator) 16-24 before cell infusion. After 4-24 weeks, animals were killed and organs were evaluated by Q-PCR for Neo (in parenthesis) and immunohistochemistry (see Fig. 6). For SR-1 and SR-2, bone marrow from animals 9 and 10 was collected, and $1.5 \times 10^{7}$ cells transplanted in secondary recipients. 

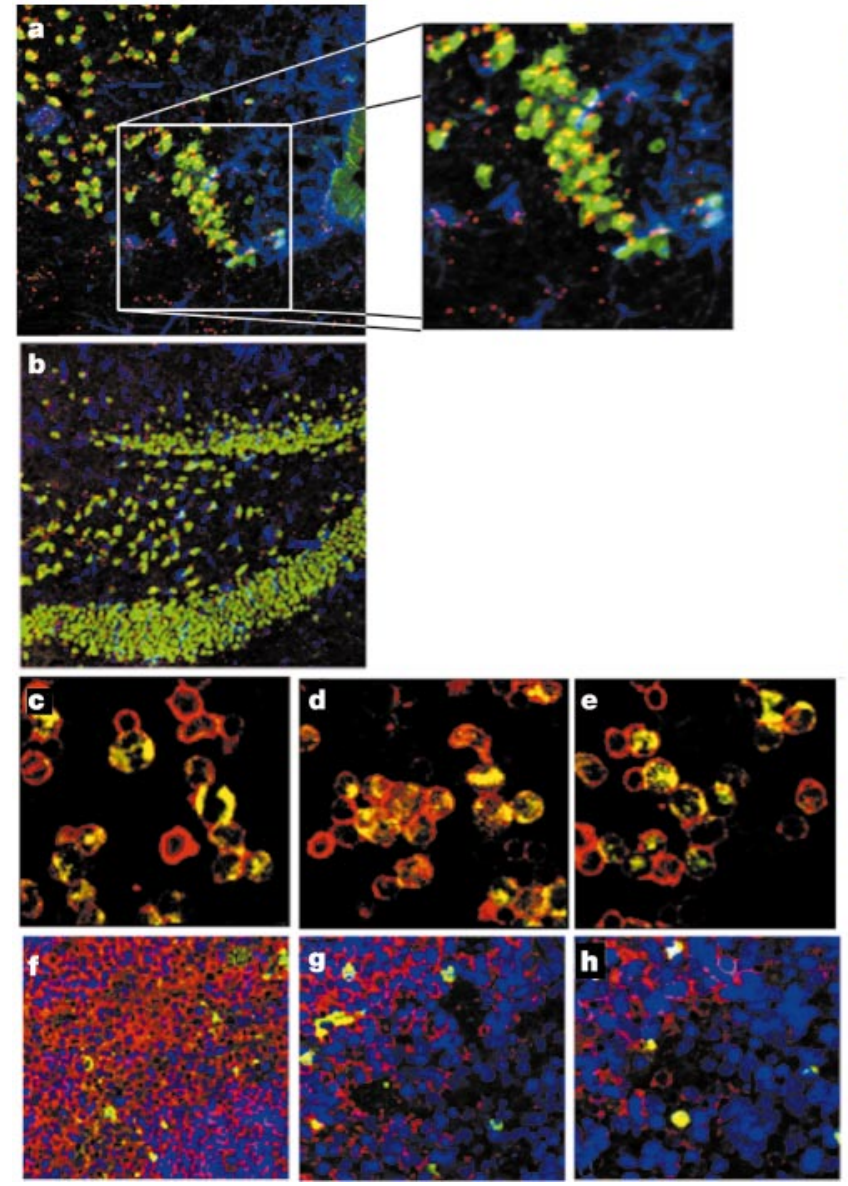
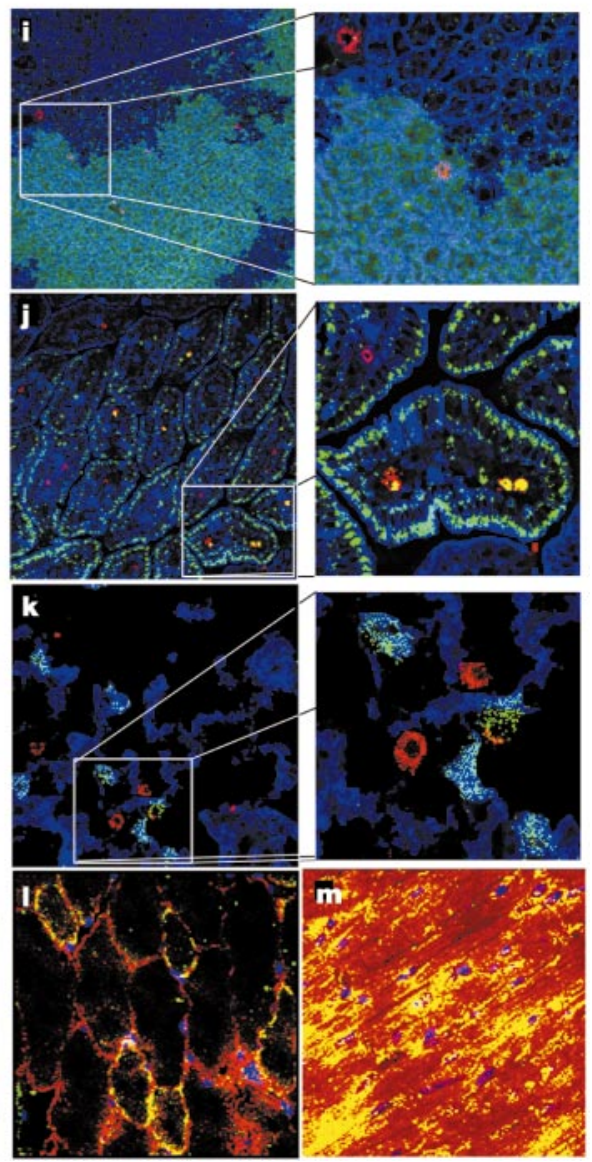

pan-CK-Cy-5. k, Lung stained with anti- $\beta$-gal-FITC, anti-CD45-PE and pan-CK-Cy-5. I, Skeletal muscle stained with anti- $\beta$-gal-FITC, anti-dystrophin-Cy3 and T0-PRO-3. $\mathbf{m}$, Heart stained with anti- $\beta$-gal-FITC, anti-cardiac troponin-I-Cy3 and TO-PRO-3. Boxed sections are shown in greater magnification in the adjacent (right) panel. Colour staining: Cy3, red; FITC, blue; Cy5, blue; TO-PRO-3, blue. Magnification: $\mathbf{a}, \times 40 ; \mathbf{b}, \times 20$; $\mathbf{c}-\mathbf{e}, \times 100 ; \mathbf{f}-\mathbf{h}, \times 60 ; \mathbf{i}-\mathbf{m}, \times 20$; all insets, $\times 60$.

Fig. 6q). These cells co-stained for CD45 (Fig. 6r), indicating that they were donor-derived haematopoietic cells. In the lung, approximately $4 \%$ of pan-CK ${ }^{+} \mathrm{CD}_{4}{ }^{-}$alveolar epithelial cells were $\beta$-gal ${ }^{+}$. A number of recipient, pan-CK ${ }^{-} \mathrm{CD}_{4} 5^{+} \beta$-gal ${ }^{-}$haematopoietic cells can also be seen in the same section (Fig. $5 \mathrm{t}$ ).

No contribution was seen to skeletal or cardiac muscle, tissues in which, in contrast to epithelium, little or no cell turnover is seen in the absence of tissue injury. Therefore, one may not expect significant contribution of stem cells to these tissues. Although mMAPCs differentiate into skin and tubular epithelium of the kidney when introduced in the blastocyst, we did not find engraftment in skin or kidney, in which epithelial cells undergo rapid turnover. Despite the ability of MAPCs to differentiate into neuroectoderm-like cells ex vivo, no significant engraftment of mMAPCs was seen in the brain, and rare donor cells found in the brain did not co-label with neuroectodermal markers. Two recent publications demonstrated that donor-derived cells with neuroectodermal characteristics were present in the brain of animals that underwent bone marrow transplantation. However, a fully ablative preparative regimen before transplantation or transplantation in newborn animals was used $^{19,22}$, conditions associated with breakdown of the blood-brain barrier. We infused cells in non-irradiated adult animals, or animals treated with a low dose of radiation, where the blood-brain barrier is intact or only minimally damaged. This may explain the lack of 

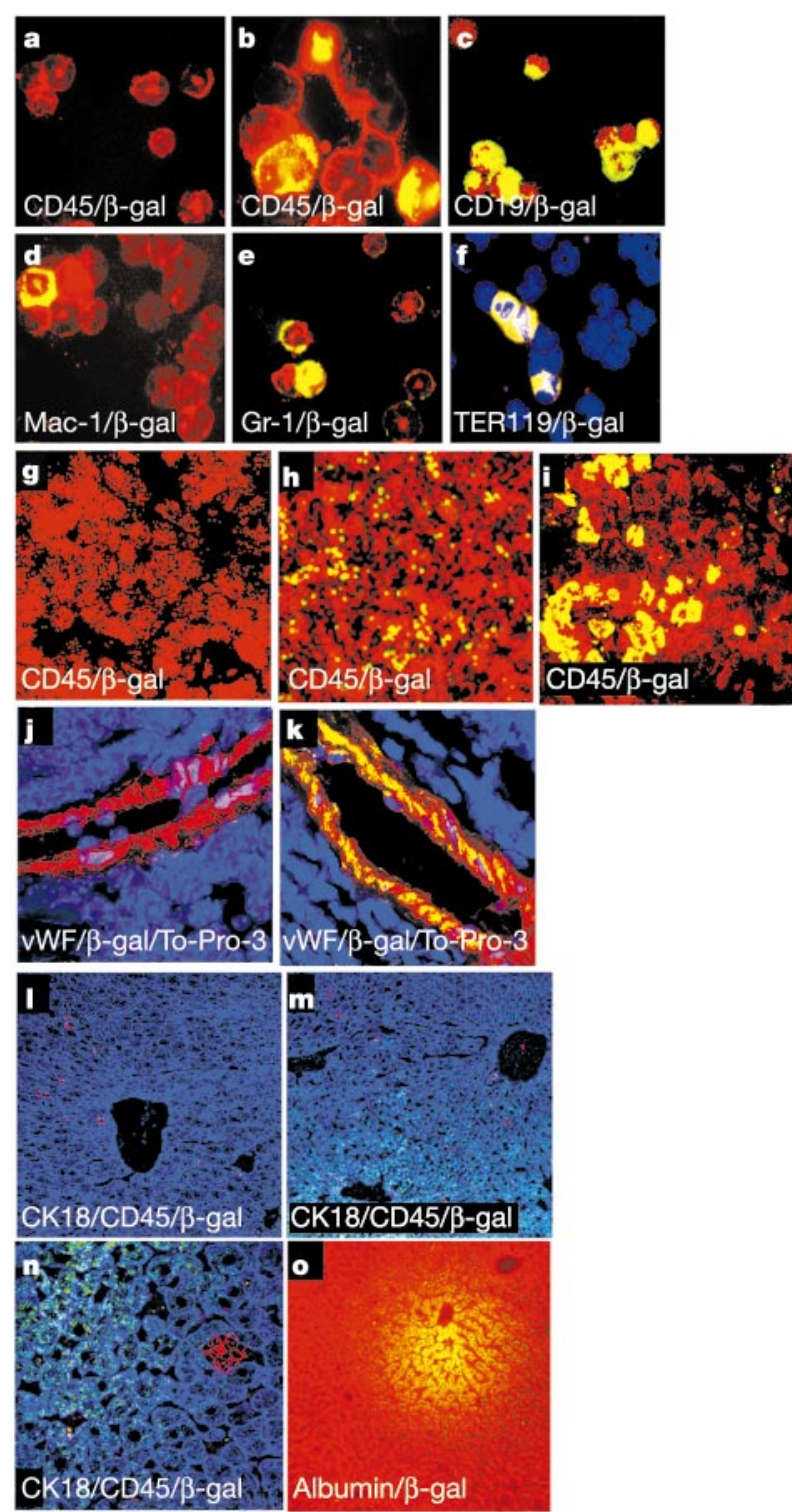

Figure 6 Engraftment and in vivo differentiation of mMAPCs. Tissue sections of a NOD/ SCID mouse (Table 2: animal 12) 11 weeks after infusion of $10^{6}$ ROSA26 MAPCs. $\mathbf{a}-\mathbf{f}$, Bone marrow (after cytospin centrifugation) of control (a) and study ( $\mathbf{b}-\mathbf{f})$ animals stained with anti- $\beta$-gal-FITC antibody and PE-conjugated antibodies to CD45 (a, b), CD19 (c), Mac-1 (d), Gr-1 (e), and TER119 and DAPI (f). $\mathbf{g}-\mathbf{i}$, Spleen of control (g) and study animals (h, i) stained with anti- $\beta$-gal-FITC and anti-CD45-PE antibodies. j, k, Blood vessel in a control mouse (j) and thymic lymphoma in a study animal 16 weeks after transplantation (k), stained with anti- $\beta$-gal-FITC, anti-vWF-PE and TO-PRO-3. I-o, Liver

mMAPC engraftment in the central nervous system.

One animal developed a lymphoma in thymus and spleen after 16 weeks, as is commonly seen in aging NOD/SCID mice ${ }^{43}$. Although the B-cell lymphoma was host-derived $\left(\mathrm{CD} 19^{+}\right.$cells were $\beta$-gal $\left.{ }^{-}\right)$, approximately $40 \%$ of $\mathrm{CD}^{2} 5^{-} \mathrm{vWF}^{+}$cells in the vasculature of the tumour stained with anti- $\beta$-gal antibodies, indicating that mMAPCs can contribute functionally to neoangiogenesis in vivo (Fig. 6k). Higher levels of mMAPC engraftment and differentiation in radiosensitive organs- - such as the haematopoietic system and intestinal epithelium (Table 2, $P<0.001$ )-after low-dose irradiation also suggests that mMAPCs may contribute functionally to host tissues. Future studies will be needed to show whether functional repopulation occurs for other tissues in the post-natal transplantation setting.

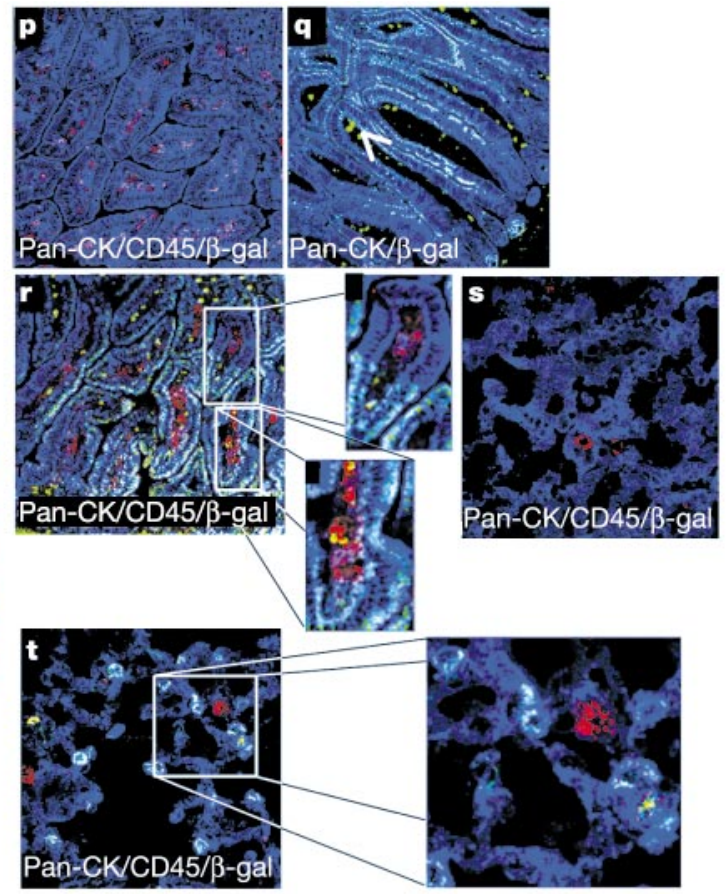

of control (I) and study animals ( $\mathbf{m}-\mathbf{0})$ stained with anti- $\beta$-gal-FITC. I-n are co-stained with anti-CK18-Cy5 plus CD45-PE and $\mathbf{o}$ with anti-albumin-Cy3. $\mathbf{p}-\mathbf{r}$, Intestine of control mouse (p) and study animal (q, r) stained with anti- $\beta$-gal-FITC plus anti-pan-CK-Cy5. The arrow in $\mathbf{q}$ shows the most haematopoietic cell. $\mathbf{p}$ and $\mathbf{r}$ are co-stained with CD45-PE antibody. $\mathbf{s}, \mathbf{t}$, Lung of control (s) and study animal (t) stained with anti- $\beta$-gal-FITC plus anti-pan-CK-Cy5 plus CD45-PE antibodies. Colour staining: Cy3, red; Cy5, blue; FITC, green; T0-PRO-3, blue; DAPI, blue. Magnification: a-f, $\times 100 ; \mathbf{g}$, i-k, $\mathbf{n}, \times 60$;

I, m, p-t, $\times 20 ; \mathbf{h}, \mathbf{0}, \times 10$; all insets, $\times 60$.

We tested whether bone marrow from primary MAPC recipients contained cells that engraft in secondary recipients. $1.5 \times 10^{7}$ bone marrow cells, recovered from primary recipients (Table 2: animal 11 and 12) 11 weeks after mMAPC infusion, were infused in secondary irradiated NOD/SCID recipients (Table 2, animal SR-1 and SR-2). After 7 and 10 weeks, secondary recipients were killed, and tissues were analysed for engraftment. A similar pattern of engraftment was seen in secondary recipients as in the primary recipients. Four to eight per cent of bone marrow, spleen and peripheral blood cells were $\beta$-gal ${ }^{+} \mathrm{CD}_{4} 5^{+} ; 6 \%$ and $8 \%$ of intestinal epithelial cells, and $4 \%$ and $5 \%$ of lung epithelial cells were $\beta$-gal ${ }^{+}$pan-CK ${ }^{+} \mathrm{CD}_{4} 5^{-}$. However, engraftment levels in the liver of secondary recipients were lower than in the primary recipients $(1 \%$ and $3 \%$ compared with $5 \%$ and $8 \% \beta-$ gal $^{+} \mathrm{CK} 18^{+}$). This suggests that mMAPCs may 
persist in the bone marrow of the primary recipient and differentiate into haematopoietic cells as well as epithelial cells when transferred to a second recipient.

As a control, we infused ROSA26 MAPCs grown to confluence before injection. MAPCs allowed to become confluent lose their ability to differentiate ex vivo in cells outside of the mesoderm, and behave like classical mesenchymal stem cells ${ }^{28}$. Infusion of $10^{6}$ confluent mMAPCs did not yield significant levels of donor cell engraftment. Although few $\beta$-gal ${ }^{+}$cells were seen in bone marrow, these cells did not co-label with anti-CD45 antibodies, indicating that mesenchymal stem cells may engraft in tissues, but are no longer able to differentiate into tissue-specific cells in response to local cues.

In contrast with ES cells, we did not detect donor-derived tumours in any of the animals. Although ES cells contribute to all tissues when injected into the blastocyst, transplantation of undifferentiated ES cells leads to the development of teratomas ${ }^{1}$, which were not seen in our model. Furthermore, intravenous infusion of ES cells does not usually lead to engraftment and tissue-specific differentiation in vivo, unless ES cells have been induced to commit to a lineage before transplantation.

\section{Discussion}

Three findings in our study address critically important questions in the field of stem cell plasticity ${ }^{44}$. In vitro and in vivo conversion of bone-marrow-derived MAPCs to endothelium, ectoderm and endoderm occurs at the single cell level. Second, the blastocyst studies indicate that MAPCs contribute functionally to most somatic tissues. Third, robust, early and persistent engraftment occurred in vivo when MAPCs were transplanted into non-damaged recipients.

We found that MAPCs require culture conditions reminiscent of ES cells, express at least some of the genetic markers of ES cells (Oct4, Rex-1, SSEA-1), have extensive proliferation and clonal multilineage differentiation potential, contribute to all organs when injected in a blastocyst, but engraft and differentiate into tissue specific cells in response to organ-specific cues. Cell fusion has recently been suggested as an explanation for stem cell plasticity. In two studies somatic cells could be induced to fuse with ES cells in vitro, generating tetraploid cells with ES-like characteristics ${ }^{45,46}$. Our in vitro studies demonstrating that single euploid MAPCs-never co-cultured with tissue-specific cells or ES cells-differentiate into cells of the three germ layers, show that the in vitro behaviour of MAPCs cannot be attributed to stem cell fusion. Although no definitive studies were done in vivo to exclude the possibility that cell fusion is responsible for the differentiation in multiple tissues, the high frequency with which chimaerism was observed and the balanced chimaerism differs from what was shown by ref. 46 . Finally, the speed and robustness with which engraftment and tissue-specific differentiation is seen in animals without need for selectable pressure, also argues against the idea that MAPC engraftment and differentiation in post-natal animals is caused by fusion.

A second possibility is that pluripotent stem cells persist even after birth in multiple organs, and that when stimulated, they proliferate and differentiate in response to local cues provided by the organ they are recruited to. A third possibility is that a tissuespecific stem cell may undergo genetic re-programming in culture similar to that which occurs in the 'cloning process ${ }^{37,48}$. Monthly cytogenetics $^{28}$ of mMAPCs and rMAPCs did not reveal abnormalities, except in one mMAPC population that became hyperdiploid at 45 population doublings, and was no longer used for studies. When mMAPCs or rMAPCs were grown to confluency, they stopped proliferating, and when cultured in serum-free medium and differentiation-inducing cytokines after 40 or more than 120 population doublings, growth arrest and terminal differentiation was seen. Furthermore, no tumour formation was seen in immunodeficient mice that received mMAPCs intravenously. Thus, even though re-programming may have occurred in vitro under the MAPC culture conditions, we have no evidence that transformation occurred.

Irrespective of their origin, MAPCs hold great promise for the treatment of degenerative or inherited diseases. Similar to ES cells, allogeneic MAPCs may be used to correct degenerative or congenital diseases. MAPCs differentiate into haematopoietic cells in vivo and can thus be used to establish haematopoietic chimaerism, which should make such an allogeneic cell therapy approach feasible. In contrast to ES cells, MAPCs can be selected from autologous bone marrow and used undifferentiated or after genetic manipulation in local or systemic therapies. Furthermore, absence of teratoma formation when undifferentiated MAPCs are infused should allow the use of undifferentiated MAPCs to treat systemic diseases, such as inherited enzyme deficiencies or muscular dystrophy.

\section{Methods \\ Antibodies used}

Antibodies against NF-200 (clone N52, 1:400), GalC (G-9152; 1:100), CK18 (C-8541; 1:300), pan-CK (C-2562; 1:100), albumin (A-6684; 1:100), GABA (A-2052, 1:500), MAP2 (AP20, 1:400), dopa-decarboxylase (DDC-109, 1:100), tyrosine hydroxylase (TH-16,

$1: 1,000$ ), serotonin (S-5545, 1:1,000), cardiac troponin-I (sc-8118, 1:100), and dystrophin (D-8168; 1:100) were from Sigma. Polyclonal antibodies against Tau, vWF, Flk-1 and hepatocyte nuclear factor (HNF)-1 were from Santa Cruz Biotechnology Inc. Antibody against GFAP was from Santa Cruz Biotechnology or DAKO Corporation. Antibody against CD31 was from BD PharMingen. Control mouse, rabbit or goat immunoglobulin$\gamma$ and FITC, Cy3-labelled secondary antibodies were from Sigma; Cy5-labelled antibodies were from Chemicon International. Donkey anti-NeuN (1:100), anti-GFAP (1:500), and anti- $\beta$-gal $(1: 2,000)$ were from Chemicon, Sigma and Cortex Biochem, respectively. Secondary anti-donkey antibodies (FITC, 1:200; Cy-3, 1:400; Cy-5, 1:200) were from Jackson Immunoresearch. Anti- $\beta$-gal-FITC antibody was from Rockland Immunochemicals. FITC- or phycoerythrin (PE)-coupled antibodies against CD45, Gr-1, Mac-1, CD19, CD3, CD13, c-Kit, Sca-1, CD34, Thy-1, Flk-1, MHC class I (H-2K $\left.{ }^{\mathrm{k}}\right)$, MHC class II $\left(\mathrm{I}-\mathrm{A}^{\mathrm{k}}\right)$, and CD44 were from BD Pharmingen, and anti-SSEA-1 antibody was from the Developmental Studies Hybridoma Bank.

\section{Differentiation culture and analysis}

Clonal $\mathrm{eGFP}^{+}$or ROSA26 mMAPCs were replated in 60\% DMEM-LG, 40\% MCDB-201, ITS, LA-BSA, $10^{-9} \mathrm{M}$ dexamethasone, $10^{-4} \mathrm{M}$ ascorbic acid 2-phosphate, $100 \mathrm{U}$ penicillin and $1,000 \mathrm{U}$ streptomycin ${ }^{28,29}$. Endothelial differentiation was induced with VEGF as described ${ }^{28,29}$. For neuroectodermal differentiation, $1 \times 10^{4}$ mMAPCs per $\mathrm{cm}^{2}$ were plated on FN with $100 \mathrm{ng} \mathrm{ml}^{-1}$ bFGF (R\&D Systems). Alternatively, cells were treated sequentially with $100 \mathrm{ng} \mathrm{ml}^{-1}$ bFGF for 7 days, $10 \mathrm{ng} \mathrm{ml}^{-1}$ FGF-8 for 7 days and $10 \mathrm{ng} \mathrm{ml}^{-1}$ BDNF for 7 days (R\&D Systems). Hepatocyte differentiation was induced as described $^{30}$. Cells were fixed with $4 \%$ paraformaldehyde and methanol at room temperature, and incubated sequentially for $30 \mathrm{~min}$ each with primary and secondary antibodies. Between steps, slides were washed with PBS/BSA. Cells were examined by confocal fluorescence microscopy (Confocal 1024 microscope; Olympus AX70, Olympus Optical Co. Ltd). To assess the frequency of different cell types in a given culture, we counted the number of cells staining positive with a given antibody in four low-power visual fields (200-500 cells per field).

\section{Tissue collection and analysis}

For the whole-mouse mount, $10-\mu \mathrm{m}$ whole-body sections near the midline were prepared as described ${ }^{41}$. Tissue sections were stained for $\beta$-galactosidase enzyme activity with the $\beta$ gal staining kit from Invitrogen at pH 7.4. Manufacturer's instructions were followed except for fixation, for which the tissue sections were incubated for $5 \mathrm{~min}$ instead of $10 \mathrm{~min}$.

A total of $0.5-1 \mathrm{ml}$ of blood was obtained when animals were killed, and bone marrow was collected by flushing femurs and tibias. For phenotyping, red blood cells and bone marrow were depleted using ice-cold ammonium chloride (Stem Cell Technologies Inc.) and $10^{5}$ cells were used for cytospin centrifugation. For serial transplantation, $1.5 \times 10^{7}$ cells from two femurs and two tibias were transplanted into individual secondary recipients by means of tail vein injection. Cytospin specimens of blood and bone marrow were fixed with acetone for $10 \mathrm{~min}$ at room temperature.

Lungs were inflated with $1 \mathrm{ml}$ 1:4 dilution of optimum cutting temperature (OCT) compound (Sakura-Finetek Inc) in PBS. Specimens of spleen, liver, lung, intestine, skeletal muscle, myocardium, kidney and brain of the recipient animals were collected and cryopreserved in OCT at $-80^{\circ} \mathrm{C}$ and in RNA Later (Ambion Inc.) at $-20^{\circ} \mathrm{C}$ for Q-PCR. Five-micrometre-thick fresh frozen sections were mounted on glass slides and fixed in acetone for $10 \mathrm{~min}$ at room temperature. After incubation with isotype sera for $20 \mathrm{~min}$, slides were stained sequentially with antibodies against cell-type antigens, anti- $\beta$-gal antibody, in some instances antibodies against CD45, or a nuclear counter stain (4,6-diamidino-2-phenylindole (DAPI) or TO-PRO-3). 
Received 30 January; accepted 21 May 2002; doi:10.1038/nature00870.

Published online 20 June 2002.

1. Thomson, J. A. et al. Embryonic stem cell lines derived from human blastocysts. Science 282, $1145-1147$ (1998)

2. Frankel, M. S. In search of stem cell policy. Science 298, 1397 (2000).

3. Weissman, I. L. Translating stem and progenitor cell biology to the clinic: barriers and opportunities. Science 287, 1442-1446 (2000).

4. Gage, F. H. Mammalian neural stem cells. Science 287, 1433-1438 (2000).

5. Potten, C. Stem cells in gastrointestinal epithelium: numbers, characteristics and death. Phil. Trans R. Soc. Lond. B 353, 821-830 (1998).

6. Watt, F. Epidermal stem cells: markers patterning and the control of stem cell fate. Phil. Trans. R. Soc Lond. B 353, 831 (1997).

7. Alison, M. \& Sarraf, C. Hepatic stem cells. J. Hepatol. 29, 678-683 (1998).

8. Pittenger, M. F. et al. Multilineage potential of adult human mesenchymal stem cells. Science $\mathbf{2 8 4}$, 143-147 (1999).

9. Ferrari, G. et al. Muscle regeneration by bone marrow-derived myogenic progenitors. Science 279, $528-530$ (1998).

10. Gussoni, E. et al. Dystrophin expression in the $\mathrm{mdx}$ mouse restored by stem cell transplantation. Nature 401, 390-394 (1999).

11. Orlic, D. et al. Bone marrow cells regenerate infarcted myocardium. Nature 410, 701-705 (2001).

12. Jackson, K. et al. Regeneration of ischemic cardiac muscle and vascular endothelium by adult stem cells. J. Clin. Invest. 107, 1395-1402 (2001).

13. Lin, Y., Weisdorf, D. J., Solovey, A. \& Hebbel, R. P. Origins of circulating endothelial cells and endothelial outgrowth from blood. J. Clin. Invest. 105, 71-77 (2000).

14. Asahara, T. et al. Bone marrow origin of endothelial progenitor cells responsible for postnatal vasculogenesis in physiological and pathological neovascularization. Circ. Res. 85, 221-228 (1999).

15. Petersen, B. E. et al. Bone marrow as a potential source of hepatic oval cells. Science 284, 1168-1170 (1999).

16. Theise, N. D. et al. Derivation of hepatocytes from bone marrow cells in mice after radiation-induced myeloablation. Hepatology 31, 235-240 (2000).

17. Lagasse, E. et al. Purified hematopoietic stem cells can differentiate into hepatocytes in vivo. Nature Med. 6, 1229-1234 (2000).

18. Krause, D. S. et al. Multi-organ, multi-lineage engraftment by a single bone marrow-derived stem cell. Cell 105, 369-377 (2001).

19. Brazelton, T. R., Rossi, F. M. V., Keshet, G. I. \& Blau, H. E. From marrow to brain: expression of neuronal phenotypes in adult mice. Science 290, 1775-1779 (2000).

20. Kopen, G., Prockop, D. \& Phinney, D. Marrow stromal cells migrate throughout forebrain and cerebellum, and they differentiate into astrocytes after injection into neonatal mouse brains. Proc. Natl Acad. Sci. USA 96, 10711-10716 (1999).

21. Mezey, E., Chandross, K. J., Harta, G., Maki, R. A. \& McKercher, S. R. Turning blood into brain: cell bearing neuronal antigens generated in vivo from bone marrow. Science 290, 1779-1782 (2000).

22. Sanchez-Ramos, J. et al. Adult bone marrow stromal cells differentiate into neural cells in vitro. Exp. Neurol. 164, 247-256 (2000)

23. Bjornson, C., Rietze, R., Reynolds, B., Magli, M. \& Vescovi, A. Turning brain into blood: a hematopoietic fate adopted by adult neural stem cells in vivo. Science 283, 354-357 (1999).

24. Morshead, C. M., Benveniste, P., Iscove, N. N. \& van der Kooy, D. Hematopoietic competence is a rare property of neural stem cells that may depend on genetic and epigenetic alterations. Nature Med. 8, 268-273 (2002).

25. Jackson, K., Mi, T. \& Goodell, M. A. Hematopoietic potential of stem cells isolated from murine skeletal muscle. Proc. Natl Acad. Sci. USA 96, 14482-14486 (1999).

26. Kawada, H. \& Ogawa, M. Bone marrow origin of hematopoietic progenitors and stem cells in murine muscle. Blood 98, 2008-2013 (2001).

27. Clarke, D. L. et al. Generalized potential of adult neural stem cells. Science 288, 1660-1663 (2000).

28. Reyes, M. et al. Purification and ex vivo expansion of postnatal human marrow mesodermal progenitor cells. Blood 98, 2615-2625 (2001).

29. Reyes, M. et al. Origin of endothelial progenitors in human post-natal bone marrow. J. Clin. Invest. 109, 337-346 (2002)

30. Schwartz, R. E. et al. Multipotent adult progenitor cells from bone marrow differentiate into functional hepatocyte-like cells. J. Clin. Invest. 109, 1291-1302 (2002).

31. Odorico, J. S., Kaufman, D. S. \& Thomson, J. A. Multilineage differentiation from human embryonic stem cell lines. Stem Cells 19, 193-204 (2001).
32. Williams, R. L. et al. Myeloid leukaemia inhibitory factor maintains the developmental potential of embryonic stem cells. Nature 336, 684-687 (1988).

33. Scholer, H. R., Hatzopoulos, A. K., Balling, R., Suzuki, N. \& Gruss, P. A family of octamer-specific proteins present during mouse embryogenesis: evidence for germline-specific expression of an Oct factor. EMBO J. 8, 2543-2550 (1989).

34. Ben-Shushan, E., Thompson, J. R., Gudas, L. J. \& Bergman, Y. Rex-1, a gene encoding a transcription factor expressed in the early embryo, is regulated via Oct- $3 / 4$ and Oct- 6 binding to an octamer site and a novel protein, Rox-1, binding to an adjacent site. Mol. Cell Biol. 18, 1866-1878 (1998).

35. Jordan, C., McKearn, J. \& Lemischka, I. Cellular and developmental properties of fetal hematopoietic stem cells. Cell 61, 953-963 (1990).

36. Nolta, J., Dao, M., Wells, S., Smogorzewska, E. \& Kohn, D. Transduction of pluripotent human hematopoietic stem cells demonstrated by clonal analysis after engraftment in immune-deficient mice. Proc. Natl Acad. Sci USA 93, 2414-2419 (1996).

37. Lenvik, T., Lund, T. C. \& Verfaillie, C. M. Blockerette-ligated capture T7 amplified RT-PCR, a new method for determining flanking sequences. Mol. Therapy (in the press).

38. Palmer, T. D., Markakis, E. A., Willhoite, A. R., Safar, F. \& Gage, F. H. Fibroblast growth factor-2 activates a latent neurogenic program in neural stem cells from diverse regions of the adult CNS. J. Neurosci. 19, 8487-8497 (1999).

39. Lee, S. H., Lumelsky, N., Studer, L., Auerbach, J. M. \& McKay, R. D. Efficient generation of midbrain and hindbrain neurons from mouse embryonic stem cells. Nature Biotechnol. 18, 675-679 (2000).

40. Zambrowicz, B. P. et al. Disruption of overlapping transcripts in the ROSA beta geo 26 gene trap strain leads to widespread expression of beta-galactosidase in mouse embryos and hematopoietic cells. Proc. Natl Acad. Sci. USA 94, 3789-3794 (1997).

41. Reinhardt, R. L., Khoruts, A., Merica, R., Zell, T. \& Jenkins, M. K. Visualizing the generation of memory CD4 T cells in the whole body. Nature 401, 101-105 (2001).

42. Weiss, M. J. \& Orkin, S. H. GATA transcription factors: key regulators of hematopoiesis. Exp. Hematol. 23, 99-107 (1995).

43. Prochazka, M., Gaskins, H. R., Shultz, L. D. \& Leiter, E. H. The nonobese diabetic scid mouse: model for spontaneous thymomagenesis associated with immunodeficiency. Proc. Natl Acad. Sci. USA 89, 3290-3294 (1992).

44. Anderson, D. J., Gage, F. H. \& Weissman, I. L. Can stem cells cross lineage boundaries? Nature Med. 7, 393-395 (2001).

45. Terada, N. et al. Bone marrow cells adopt the phenotype of other cells by spontaneous cell fusion. Nature 416, 542-545 (2002); advance online publication, 13 March 2002 (doi:10.1038/nature00730).

46. Ying, Q. Y., Nichols, J., Evans, E. P. \& Smith, A. G. Changing potency by spontaneous fusion. Nature 416, 545-548 (2002); advance online publication, 13 March 2002 (doi:10.1038/nature729).

47. Rideout, W. M. et al. Generation of mice from wild-type and targeted ES cells by nuclear cloning. Nature Genet. 24, 109-110 (2000)

48. Wilmut, I., Schnieke, A. E., McWhir, J., Kind, A. J. \& Campbell, K. H. Viable offspring derived from fetal and adult mammalian cells. Nature 385, 810-813 (1997).

49. Pear, W. S. et al. Efficient and rapid induction of a chronic myelogenous leukemia-like myeloproliferative disease in mice receiving P210 bcr/abl-transduced bone marrow. Blood 92, 3780-3792 (1998).

Supplementary Information accompanies the paper on Nature's website (http://www.nature.com/nature).

\section{Acknowledgements}

The authors wish to thank M. Jenkins for technical support. This work was supported by NIH grants, the Michael J. Fox Foundation, the Children's Cancer Research Fund, the Tulloch Family Foundation, and the McKnight Foundation. R.E.S., C.D.K., X.R.O.-G. and M.R. are supported by the NIH-MSTP programme at the University of Minnesota.

\section{Competing interests statement}

The authors declare competing financial interests: details accompany the paper on Nature's website (http://www.nature.com/nature).

Correspondence and requests for materials should be addressed to C.M.V.

(e-mail: verfa001@umn.edu). 